\title{
Alzheimer's data lawsuit is sign of growing tensions
}

\section{Battle between California universities raises questions about research ownership.}

\section{BY ERIKA CHECK HAYDEN}

$\mathrm{I}$ $\mathrm{n}$ a case that highlights growing tensions over who controls scientific data after faculty members move on, a California university has sued a researcher who left for another institution in June, alleging that he and colleagues conspired to hijack a valuable trove of Alzheimer's data. The researcher insists that he acted properly.

On 2 July, the University of California, San Diego (UCSD), filed a lawsuit alleging that when Alzheimer's researcher Paul Aisen took a new job at the University of Southern California (USC), he improperly tried to take with him a large clinical-trials programme that he was leading.

Aisen ran the Alzheimer's Disease Cooperative Study (ADCS), a 24-year-old clinical-trials network, at UCSD from 2007 until 21 June, when he left for USC. Within two weeks, UCSD sued Aisen, colleagues who left with him, and USC, alleging a conspiracy to transfer contracts and data related to the ADCS. The researchers are also accused of blocking their colleagues back at UCSD from "administrative control" of the ADCS database.

\section{DATA DISPUTE}

UCSD says that Aisen's alleged attempt to transfer the study and data without UCSD's permission is neither legal nor usual. "When a researcher leaves a university, there is always proper notification and a transition plan. None of which occurred here. Never does a researcher simply take control of data without permission from the university, the grant sponsors and the [US National Institutes of Health]," says UCSD health-sciences spokesperson Jacqueline Carr.

Aisen counters that he left UCSD after what he saw as long-standing difficulties with running the ADCS there. "I did not feel that our research had the necessary support at UCSD," he told Nature. He says that he did nothing out of the ordinary when he left UCSD, that he remains co-principal investigator on several clinical trials that are coordinated by the ADCS, and that UCSD still has access to the study network's data.

Aisen adds that several times before and after his departure, he asked UCSD to allow

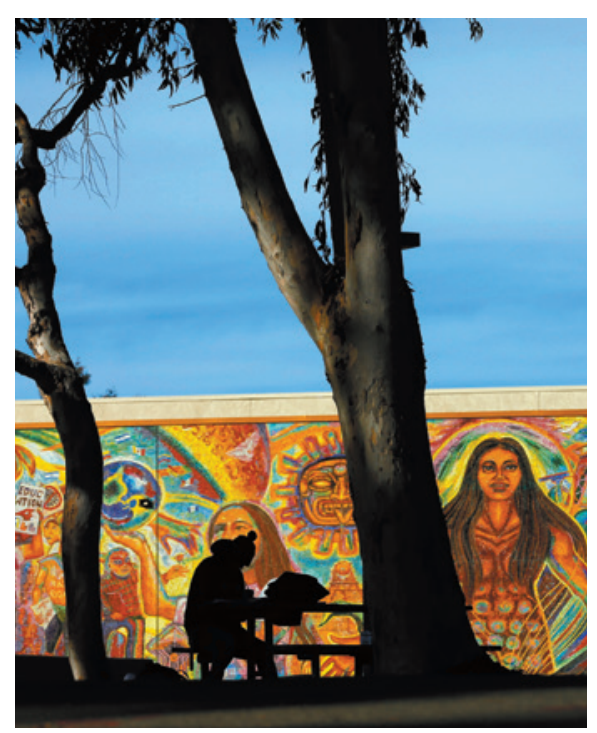

The campus of University of California, San Diego, which hosted a major Alzheimer's project.

him to transfer the ADCS programme, but that these requests were rebuffed. "The reason given was, this programme will always be at UCSD, period," Aisen told Nature.

Legal disputes over the ownership of data are not unheard of. But such arguments are escalating as universities become more involved in the development of treatments, a trend driven by diminishing funding by pharmaceutical companies for work to bridge the 'valley of death' between basic research and clinical trials.

The ADCS is not a single study, but a network that coordinates 11 clinical trials in Alzheimer's disease, involving researchers at 70 institutions in the United States and Canada. The US National Institute on Aging in 2013 awarded UCSD and Aisen up to US $\$ 55$ million to run the ADCS until 2018. Two companies, Eli Lilly of Indianapolis, Indiana, and the Japan-based Toyama Chemical, currently sponsor clinical trials coordinated by the ADCS. UCSD estimates in its lawsuit that the total funding for studies under the ADCS's umbrella is more than $\$ 100$ million.

The university also alleges that Aisen began discussing moving to USC in April, that he discussed a transfer of the Alzheimer's study to USC, and that his staff discussed with
Toyama the possibility of transferring its contract from UCSD to USC.

The complaint further alleges that Aisen notified UCSD by e-mail on 18 June of his intent to depart for USC on 1 July, and that in-house lawyers for UCSD then advised Aisen not to take with him "equipment, records, electronic data or software that were purchased or created for the ADCS at UC San Diego". Then, says the lawsuit, Aisen sent another e-mail on 21 June declaring his immediate resignation. Some of the Alzheimer's cooperative study staff changed administrative access codes and passwords for databases maintained through the study, the complaint alleges, and then abruptly resigned themselves.

Aisen says that his staff retained administrative control over the ADCS database to maintain the integrity of highly regulated clinical trial data. He denies that his staff changed passwords. "That claim is not true," he told Nature.

\section{FUNDING WOES}

In a court filing, Aisen states that he left UCSD because of "funding delays and shortfalls that I believe hampered the work of ADCS". For instance, he says that he had too few staff to help the ADCS to negotiate contracts and salary restrictions, which "impacted ADCS's hiring abilities". The court has received letters supporting Aisen's oversight of individual studies and of ADCS data from colleagues at Harvard Medical School in Boston, Massachusetts; Yale University School of Medicine in New Haven, Connecticut; Wake Forest School of Medicine in Winston-Salem, North Carolina; and from Lilly.

According to UCSD's lawsuit, USC offered Aisen a $\$ 500,000$ annual salary until 2020, as well as low- and no-interest home loans that would be partially forgiven over time. Aisen told Nature that salary and compensation were never part of his discussion with USC.

"I was surprised that Paul Aisen abruptly decided to take a better offer, but I understand it perfectly," says Jeanne Loring, a neuroscientist and stem-cell researcher at the Scripps Research Institute in La Jolla, California. "Funding is so uncertain; having the opportunity to follow through on what you've been working on in science is attractive. I would have done the same thing." - 